\title{
Article
}

\section{Cubic Nonlinear Optical Properties of Platinum-Terminated Polyynediyl Chains}

Marek Samoc, Gulliver T. Dalton, John A. Gladysz, Qinglin Zheng, Yasen Velkov, Hans Ågren, Patrick Norman, and Mark G. Humphrey Inorg. Chem., 2008, 47 (21), 9946-9957 • DOI: 10.1021/ic801145c • Publication Date (Web): 01 October 2008

Downloaded from http://pubs.acs.org on January 26, 2009

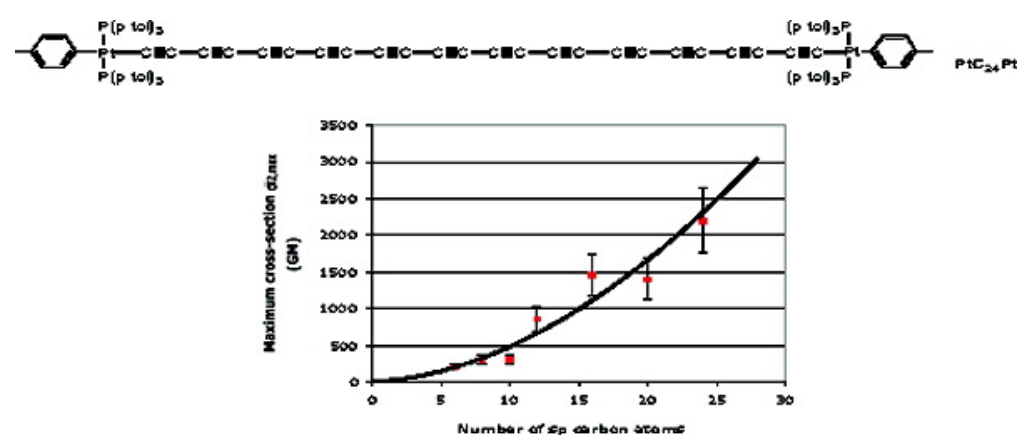

\section{More About This Article}

Additional resources and features associated with this article are available within the HTML version:

- Supporting Information

- Access to high resolution figures

- $\quad$ Links to articles and content related to this article

- Copyright permission to reproduce figures and/or text from this article

\section{View the Full Text HTML}




\title{
Cubic Nonlinear Optical Properties of Platinum-Terminated Polyynediyl Chains
}

\author{
Marek Samoc, ${ }^{, \dagger}$ Gulliver T. Dalton, ${ }^{\dagger, \ddagger}$ John A. Gladysz, ${ }^{,, \S, \|}$ Qinglin Zheng, ${ }^{\S}$ Yasen Velkov, ${ }^{\perp}$ \\ Hans Ågren, ${ }^{, \perp \perp}$ Patrick Norman, ${ }^{\#}$ and Mark G. Humphrey, ${ }^{*, \$,}$ \\ Laser Physics Centre, Australian National University, Canberra ACT 0200, Australia, Department \\ of Chemistry, Australian National University, Canberra ACT 0200, Australia, Institut für \\ Organische Chemie and Interdisciplinary Center for Molecular Materials, Friedrich-Alexander \\ Universität Erlangen-Nürnberg, Henkestrasse 42, 91054 Erlangen, Germany, Department of \\ Chemistry, Texas A\&M University, P.O. Box 30012, College Station, Texas 77842-3012, \\ Department of Theoretical Chemistry, Royal Institute of Technology, Roslagstullsbacken 15, \\ S-106 91 Stockholm, Sweden, and Department of Physics, Chemistry and Biology, Linköping \\ University, SE-581 83 Linköping, Sweden
}

Received June 21, 2008

The wavelength dependence of the cubic nonlinearity of ligated platinum-terminated polyynes trans,trans $-\{(p-$ $\left.\left.\mathrm{MeC}_{6} \mathrm{H}_{4}\right)_{3} \mathrm{P}\right\}_{2}\left(p-\mathrm{MeC}_{6} \mathrm{H}_{4}\right) \mathrm{Pt}(\mathrm{C} \equiv \mathrm{C})_{n} \mathrm{Pt}\left(p-\mathrm{C}_{6} \mathrm{H}_{4} \mathrm{Me}\right)\left\{\mathrm{P}\left(p-\mathrm{C}_{6} \mathrm{H}_{4} \mathrm{Me}\right)_{3}\right\}_{2} \quad(n=3-6,8,10,12)$ has been examined by femtosecond Z-scan studies in the wavelength range $520-1500 \mathrm{~nm}$ and the results rationalized by density functional theory calculations on the model complexes trans,trans- $\left(\mathrm{H}_{3} \mathrm{P}\right)_{2}\left(\mathrm{C}_{6} \mathrm{H}_{5}\right) \mathrm{Pt}(\mathrm{C} \equiv \mathrm{C})_{n} \mathrm{Pt}\left(\mathrm{C}_{6} \mathrm{H}_{5}\right)\left(\mathrm{PH}_{3}\right)_{2}(n=2-8,10,12)$. Although the final states for one- and two-photon transitions are not the same in these centrosymmetric molecules, the Z-scan studies reveal coincidences in one-photon absorption with features in the frequency dependencies of both real and imaginary parts of the cubic hyperpolarizability, as well as inflections in the frequency dependencies of the real part of $\gamma$ that correspond to resonances in the imaginary part of $\gamma$. The theoretical studies suggest that the linear absorption spectra are dominated by $X^{1} A_{g} \rightarrow n^{1} B_{3 u}$ transitions, with the first state of $B_{3 u}$ symmetry playing a steadily diminishing role upon oligoyne chain lengthening. The theoretical studies also predict a red-shift of two-photon absorption (TPA) profile with increasing conjugation length, and a significant enhancement on proceeding from the shortest to the longest chromophore, trends that are observed experimentally. The experimental low-energy TPA maxima for these complexes can be approximated by a simple Gaussian profile. The sp-carbon chain-length dependence of linear and nonlinear absorption maxima enable an estimate (neglecting saturation) of 660 and $1000 \mathrm{~nm}$ for the infinite carbon chain, carbyne.

\section{Introduction}

Over the last two decades, there has been tremendous growth in the numbers and types of isolable carbon allot-

* To whom correspondence should be addressed. (M.S.) E-mail: Marek.Samoc@anu.edu.au. Phone: +61 26125 4611. Fax: +61 26125 0029. (J.A.G.) E-mail: gladysz@mail.chem.tamu.edu or John.Gladysz@ chemie.uni-erlangen.de. Phone: +1 979845 1399. Fax: +1 9798454719. (H.A.) E-mail: agren@TheoChem.kth.se. Phone: +46 85537 8416. Fax: +46 85537 8590. (M.G.H.) E-mail: Mark.Humphrey@anu.edu.au. Phone: +6126125 2927. Fax: +61261250760.

Laser Physics Centre, Australian National University.

$\doteqdot$ Department of Chemistry, Australian National University.

$\S$ Friedrich-Alexander Universität Erlangen-Nürnberg.

"Texas A\&M University.

${ }^{\perp}$ Royal Institute of Technology.

\# Linköping University. ropes. ${ }^{1}$ However, an obvious conceptual partner to the historically important $\mathrm{sp}^{3}$ - and $\mathrm{sp}^{2}$-hybridized polymeric allotropes, diamond and graphite, namely carbyne, the sphybridized linear polymer, ${ }^{2}$ has remained an elusive goal. The electronic and optical behavior of an infinite sp carbon chain is clearly of broad fundamental interest. To probe the properties of this hypothetical or challenging-to-define spe-

(1) (a) Diederich, F.; Rubin, Y. Angew. Chem., Int. Ed. Engl. 1992, 31, 1101; Angew. Chem. 1992, 104, 1123. (b) Heimann, R. B.; Evsyukov, S. E.; Koga, Y. Carbon 1997, 35, 1654. (c) Hirsch, A.; Brettreich, M. Fullerenes: Chemistry and Reactions; Wiley/VCH: Weinheim, 2004.

(2) (a) Tobe, Y.; Wakabayashi, T. In Acetylene Chemistry; Diederich, F., Stang, P. J., Tykwinski, R. R., Eds.; Wiley/VCH: Weinheim, 2004; Chapter 9. (b) Polyynes: Synthesis, Properties and Applications; Cataldo, F., Ed.; Taylor \& Francis: New York, 2005. 
cies, several research groups have prepared series of longchain conjugated polyynes or polyynediyls that are endfunctionalized with organic or inorganic capping units. ${ }^{3-7}$ These impart sufficient stability for detailed physical studies, allowing the properties of carbyne to be predicted by plotting measurable quantities as a function of chain length, as exemplified by a recent in-depth structural analysis. ${ }^{8}$

The principal modern studies of such series have originated from the laboratories of Hirsch, ${ }^{5}$ Tykwinski, ${ }^{6}$ and one of the present authors. ${ }^{7}$ There are also a number of older papers with important UV/visible and/or IR data, for which the highest homologues are often generated in situ. ${ }^{3,4}$ Several theoretical studies have also appeared. ${ }^{9}$ Given the focus of this work on species with inorganic endgroups, references to metal polyynediyl complexes consisting of at least six $\mathrm{C} \equiv \mathrm{C}$ units are also provided. ${ }^{7,10-13}$ Several systems for which the redox properties have been particularly well characterized also deserve note. ${ }^{7 \mathrm{a}, 11 \mathrm{~d}, 14}$

As is clear from the preceding discussion, evolution of the linear optical properties as a function of oligoyne chain length is of particular interest. This has been studied for

(3) (a) Jones, E. R. H.; Lee, H. H.; Whiting, M. C. J. Chem. Soc. 1960, 3483. (b) Johnson, T. R.; Walton, D. R. M. Tetrahedron 1972, 28, 5221.

(4) Eastmond, R.; Johnson, T. R.; Walton, D. R. M. Tetrahedron 1972, 28,4601 .

(5) (a) Schermann, G.; Grösser, T.; Hampel, F.; Hirsch, A. Chem.-Eur. J. 1997, 3, 1105. (b) Gibtner, T.; Hampel, F.; Gisselbrecht, J.-P.; Hirsch, A. Chem.-Eur. J. 2002, 8, 408. (c) Klinger, C.; Vostrowsky, O.; Hirsch, A. Eur. J. Org. Chem. 2006, 1508.

(6) (a) Luu, T.; Elliot, E.; Slepkov, A. D.; Eisler, S.; McDonald, R.; Hegmann, F. A.; Tykwinski, R. R. Org. Lett. 2005, 7, 51. (b) Eisler, S.; Slepkov, A. D.; Elliot, E.; Luu, T.; McDonald, R.; Hegmann, F. A.; Tykwinski, R. R. J. Am. Chem. Soc. 2005, 127, 2666. (c) Chalifoux, W. A.; Ferguson, M. J.; Tykwinski, R. R. Eur. J. Org. Chem. 2007, 1001. (d) Slepkov, A. D.; Hegmann, F. A.; Eisler, S.; Elliot, E.; Tykwinski, R. R. J. Chem. Phys. 2004, 129, 6807.

(7) (a) Dembinski, R.; Bartik, T.; Bartik, B.; Jaeger, M.; Gladysz, J. A. J. Am. Chem. Soc. 2000, 122, 810. (b) Mohr, W.; Stahl, J.; Hampel, F.; Gladysz, J. A. Chem.-Eur. J. 2003, 9, 3324. (c) Zheng, Q.; Gladysz, J. A. J. Am. Chem. Soc. 2005, 127, 10508. (d) Zheng, Q.; Bohling, J. C.; Peters, T. B.; Frisch, A. C.; Hampel, F.; Gladysz, J. A. Chem.-Eur. J. 2006, 12, 6486.

(8) Szafert, S.; Gladysz, J. A. Chem. Rev. 2003, 103, 4175; 2006, 106, PR1-PR33.

(9) Studies treating $(\mathrm{C} \equiv \mathrm{C})_{6}$ or higher systems: (a) Horny', $\hat{\mathrm{L}}$; Petraco, N. D. K.; Pak, C.; Schaefer, H. F., III. J. Am. Chem. Soc. 2002, 124, 5861. (b) Neugebauer, J.; Reiher, M. J. Phys. Chem. A 2004, 108, 2053. (c) Cao, Z.; Qianer, Z. Chem.-Eur. J. 2004, 10, 1920. (d) Zhuravlev, F.; Gladysz, J. A. Chem.-Eur. J. 2004, 10, 6510. (e) Herrmann, C.; Neugebauer, J.; Gladysz, J. A.; Reiher, M. Inorg. Chem. 2005, 44, 6174.

(10) $\mathrm{FeC}_{12} \mathrm{Fe}$ complex Sakurai, A.; Akita, M.; Moro-oka, Y. Organometallics 1999, 18, 3241.

(11) $\mathrm{RuC}_{14} \mathrm{Ru}$ complex: (a) Antonova, A. B.; Bruce, M. I.; Ellis, B. G.; Gaudio, M.; Humphrey, P. A.; Jevric, M.; Melino, G.; Nicholson, B. K.; Perkins, G. J.; Skelton, B. W.; Stapleton, B.; White, A. H.; Zaitseva, N. N. Chem. Commun. 2004, 960. RuC ${ }_{12}$ Ru complex: (b) Rigaut, S.; Perruchon, J.; Le Pichon, L.; Touchard, D.; Dixneuf, P. H. J. Organomet. Chem. 2003, 670, 37. $\mathrm{RuC}_{12} \mathrm{Ru}$ complex: (c) Qi, H.; Gupta, A.; Noll, B. C.; Snider, G. L.; Lu, Y.; Lent, C.; Fehlner, T. P. J. Am. Chem. Soc. 2005, 127, 15218. $\mathrm{RuC}_{12} \mathrm{Ru}$ complex: (d) Xu, G.L.; Wang, C.-Y.; Ni, Y.-H.; Goodson, T. G., III.; Ren, T. Organometallics 2005, 24, 3427.

(12) $\mathrm{RhC}_{12}$ Rh complex: Xu, G.-Y.; Zou, G.; Ni, Y.-H.; DeRosa, M. C.; Crutchley, R. J.; Ren, T. J. Am. Chem. Soc. 2003, 125, 10057.

(13) $\mathrm{PtC}_{12} \mathrm{Pt}$ complexes (in addition to those in references $7 \mathrm{~b}-\mathrm{d}$ ): (a) Stahl, J.; Mohr, W.; de Quadras, L.; Peters, T. B.; Bohling, J. C.; MartínAlvarez, J. M.; Owen, G. R.; Hampel, F.; Gladysz, J. A. J. Am. Chem. Soc. 2007, 129, 8282. (b) de Quadras, L.; Bauer, E. B.; Mohr, W.; Bohling, J. C.; Peters, T. B.; Martín-Alvarez, J. M.; Hampel, F.; Gladysz, J. A. J. Am. Chem. Soc. 2007, 129, 8296. several systems (vide supra); while $\lambda_{\max }$ generally red-shifts with increasing chain length to reach a value $\lambda_{\text {sat }}$ that has been used to provide an estimate of the highest occupied molecular orbital (HOMO)-lowest unoccupied molecular orbital (LUMO) gap in carbyne, the $\varepsilon$ values are strongly dependent on the nature of the end-group. ${ }^{6 b}$ In contrast, nonlinear optical (NLO) properties are little-studied, and the data that exist derive from experiments at one laser irradiation wavelength. The molecular second hyperpolarizabilities of silyl-terminated oligoynes $\operatorname{Pr}_{3}{ }_{3} \operatorname{Si}(\mathrm{C} \equiv \mathrm{C})_{n} \operatorname{SiPr}_{3}{ }_{3}(n=2-6,8$, 10: see Chart 1) were assessed by differential optical Kerr effect studies employing $100 \mathrm{fs}$ pulses at $800 \mathrm{~nm}$, with nonlinearities following the power law $\gamma=a+b n^{c}$ for an oligoyne with $n \mathrm{C} \equiv \mathrm{C}$ units, an offset $a$ resulting from the nonlinearity of the triisopropylsilyl units, and $c=4.28$ significantly higher than that predicted theoretically for polyynes $(1.26-3.3){ }^{6 b}$ However, comparisons of optical nonlinearity for related compounds at a single wavelength have the shortcoming that there is no certainty to what extent the data are skewed by the resonant enhancement; to estimate the electronic nonlinearity of carbyne, NLO wavelength dependence studies of compounds of systematically increasing sp-carbon chain length are needed. Extending our longstanding interest in NLO properties of organometallic complexes, ${ }^{15,16}$ and the considerable interest shown in NLO properties of platinum alkynyl complexes ${ }^{17}$ we report herein wavelength dependence studies of the complex cubic nonlinearity of ligated platinum-terminated oligoynes across the broad spectral range $520-1500 \mathrm{~nm}$, together with theoretical studies on model complexes directed at understanding our experimental results.

\section{Experimental Section}

NLO Measurements. The complexes trans, trans- $\left\{\left(p-\mathrm{MeC}_{6} \mathrm{H}_{4}\right)_{3}-\right.$ $\mathrm{P}_{2}\left(p-\mathrm{MeC}_{6} \mathrm{H}_{4}\right) \mathrm{Pt}(\mathrm{C} \equiv \mathrm{C})_{n} \mathrm{Pt}\left(p-\mathrm{C}_{6} \mathrm{H}_{4} \mathrm{Me}\right)\left\{\mathrm{P}\left(p-\mathrm{C}_{6} \mathrm{H}_{4} \mathrm{Me}\right)_{3}\right\}_{2}[n=3$ $\left(\mathbf{P t C}_{6} \mathbf{P t}\right), 4\left(\mathbf{P t C}_{8} \mathbf{P t}\right), 5\left(\mathbf{P t C}_{10} \mathbf{P t}\right), 6\left(\mathbf{P t C}_{12} \mathbf{P t}\right), 8\left(\mathbf{P t C}_{16} \mathbf{P t}\right), 10$ $\left(\mathbf{P t C}_{20} \mathbf{P t}\right), 12\left(\mathbf{P t C}_{24} \mathbf{P t}\right)$ : Chart 2] were prepared following the published procedure, ${ }^{7 \mathrm{~d}}$ and their NLO properties investigated over a wide spectral range using the $\mathrm{Z}$-scan technique. ${ }^{18}$ The compounds were dissolved in dichloromethane at concentrations in the range $0.1-1 \% \mathrm{w} / \mathrm{w}$ and the solutions were placed in $1 \mathrm{~mm}$ path length Starna glass cells, stoppered and sealed with Teflon tape. Because of experimental limitations, only one concentration of each compound was examined. The Z-scans were carried out using a femtosecond laser system composed of a Clark-MXR CPA-2001 regenerative amplifier acting as a $775 \mathrm{~nm}$ pump and a Light Conversion TOPAS optical parametric amplifier. The system was operated at a repetition rate of $83 \mathrm{~Hz}$ to minimize the influence of

(14) (a) Bruce, M. I.; Low, P. J.; Costuas, K.; Halet, J.-F.; Best, S. P.; Heath, G. A. J. Am. Chem. Soc. 2000, 122, 1949. (b) Paul, F.; Meyer, W. E.; Toupet, L.; Jiao, H.; Gladysz, J. A.; Lapinte, C. J. Am. Chem. Soc. 2000, 122, 9405. (c) Coat, F.; Paul, F.; Lapinte, C.; Toupet, L.; Costuas, K.; Halet, J.-F. J. Organomet. Chem. 2003, 683, 368. (d) Venkatesan, K.; Blacque, O.; Berke, H. Dalton Trans. 2007, 1091 (a review).

(15) Reviews: (a) Whittall, I. R.; McDonagh, A. M.; Humphrey, M. G.; Samoc, M. Adv. Organomet. Chem. 1998, 42, 291. (b) Whittall, I. R.; McDonagh, A. M.; Humphrey, M. G.; Samoc, M. Adv. Organomet. Chem. 1999, 43, 349. (c) Powell, C. E.; Humphrey, M. G. Coord. Chem. Rev. 2004, 248, 725. (d) Morrall, J. P.; Dalton, G. T.; Humphrey, M. G.; Samoc, M. Adv. Organomet. Chem. 2007, 55, 61. 
Chart 1. Polyyne Compounds for Which Second Hyperpolarizabilities Have Been Reported ${ }^{6 b}$

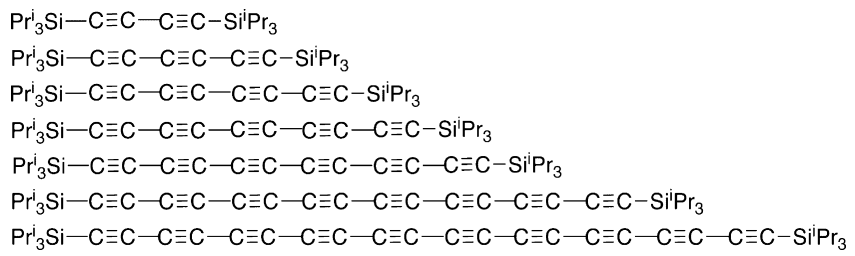

thermal effects ${ }^{19}$ and photochemical decomposition. The experiments were carried out at a number of wavelengths in the range 520-1500 $\mathrm{nm}$. To obtain the relevant wavelengths, the optical parametric amplifier was appropriately tuned and one of the following modes of output was selected: idler-pump mixing, signal doubling, idler doubling, or the signal. The unwanted components of the TOPAS output were discarded through the use of polarizing optics, color glass filters, and spatial filtering.

The laser beam was attenuated to energies in the $\mu \mathrm{J} /$ pulse range and directed through a standard Z-scan setup equipped with a beam splitter, allowing one to record open-aperture and closed-aperture Z-scans simultaneously. The beam was focused so as to provide a spot size in the range $w_{0} \approx 40-80 \mu \mathrm{m}$, ensuring that the Rayleigh range $z_{\mathrm{R}}=\pi w_{0}^{2} / \lambda$ was always larger than the total thickness of the sample $(\approx 3 \mathrm{~mm}$ which includes two glass walls and the solution inside the cell). ${ }^{19}$ The scan range was usually $z=-40$ to $40 \mathrm{~mm}$ and the data were recorded using three $\mathrm{Si}$ or InGaAs photodiodes monitoring the input pulse energy, the open aperture signal, and the closed aperture signal, respectively, whose outputs were fed into three channels of a boxcar averager, which was GPIB-interfaced with a data collection computer. The shapes of the closed-aperture scans, open-aperture scans, and the curves obtained by dividing a closed-aperture curve by an open-aperture curve were analyzed with the help of a custom fitting program that used equations derived by Sheik-Bahae et al. ${ }^{18}$ to calculate the theoretical curves. In this way the values of the real and imaginary part of the nonlinear phase shift $\Delta \Phi_{0}$ (corresponding to the refractive and absorptive nonlin-

(16) Selected references: (a) Whittall, I. R.; Humphrey, M. G.; Samoc, M.; Luther-Davies, B. Angew. Chem., Int. Ed. Engl. 1997, 36, 370. (b) McDonagh, A. M.; Humphrey, M. G.; Samoc, M.; Luther-Davies, B.; Houbrechts, S.; Wada, T.; Sasabe, H.; Persoons, A. J. Am. Chem. Soc. 1999, 121, 1405. (c) Powell, C. E.; Cifuentes, M. P.; Morrall, J. P. L.; Stranger, R.; Humphrey, M. G.; Samoc, M.; Luther-Davies, B.; Heath, G. A. J. Am. Chem. Soc. 2003, 125, 602. (d) Powell, C. E.; Morrall, J. P.; Ward, S. A.; Cifuentes, M. P.; Notaras, E. G. A.; Samoc, M.; Humphrey, M. G. J. Am. Chem. Soc. 2004, 126, 12234. (e) Cifuentes, M. P.; Powell, C. E.; Morrall, J. P.; McDonagh, A. M.; Lucas, N. T.; Humphrey, M. G.; Samoc, M.; Houbrechts, S.; Asselberghs, I.; Clays, K.; Persoons, A.; Isoshima, T. J. Am. Chem. Soc. 2006, 128, 10819. (f) Samoc, M.; Gauthier, N.; Cifuentes, M. P.; Paul, F.; Lapinte, C.; Humphrey, M. G. Angew. Chem., Int. Ed. 2006, 118, 7536. (g) Samoc, M.; Morrall, J. P.; Dalton, G. T.; Cifuentes, M. P.; Humphrey, M. G. Angew. Chem., Int. Ed. 2007, 46, 731. (h) Dalton, G. T.; Cifuentes, M. P.; Petrie, S.; Stranger, R.; Humphrey, M. G.; Samoc, M. J. Am. Chem. Soc. 2007, 129, 11882.

(17) (a) Frazier, C. C.; Guha, S.; Chen, W. P.; Cockerham, M. P.; Porter, P. L.; Chauchard, E. A.; Lee, C. H. Polymer 1987, 28, 553. (b) Frazier, C. C.; Chauchard, E. A.; Cockerham, M. P.; Porter, P. L. Mater. Res. Soc. Symp. Proc. 1988, 109, 323. (c) Guha, S.; Frazier, C. C.; Kang, K.; Finberg, S. E. Opt. Lett. 1989, 14, 952. (d) Frazier, C. C.; Guha, S.; Chen, W. P.C.T. Int. Appl. WO 89 01,182, Feb. 1989; U.S. Appl. 81,785, Aug. 1987; Chem. Abstr. 1989, 111, 105446p. (e) Page, H.; Blau, W.; Davey, A. P.; Lou, X.; Cardin, D. J. Synth. Met. 1994, 63, 179. (f) Davey, A. P.; Page, H.; Blau, W.; Byrne, H. J.; Cardin, D. J. Synth. Met. 1993, 57, 3980. (g) Zhou, G.-J.; Wong, W.-Y.; Ye, C.; Lin, Z. Adv. Funct. Mater. 2007, 17, 963.

(18) Sheikh-bahae, M.; Said, A. A.; Wei, T.; Hagan, D. J.; van Stryland, E. W. IEEE J. Quantum Electr. 1990, 26, 760.

(19) Samoc, M.; Samoc, A.; Luther-Davies, B.; Humphrey, M. G.; Wong, M.-S. Opt. Mater. 2003, 21, 485. earity, respectively) could be obtained. At each wavelength the energy of the laser pulses was fine-tuned based on closed-aperture Z-scans obtained for $1 \mathrm{~mm}$ cells filled with the solvent alone and/ or scans for a $3 \mathrm{~mm}$ thick silica glass plate. Typically, we required $\Delta \Phi_{0}$ for such scans to be about $0.5-1 \mathrm{rad}$. The nonlinear refractive index of silica, $n_{2}$, is close to $3 \times 10^{-16} \mathrm{~cm}^{2} / \mathrm{W}$ for a wide wavelength range, ${ }^{20}$ so the real part of the nonlinear phase shift can be used to calculate the light intensity, $I$, from the relation $\Delta \Phi_{0}=2 \pi n_{2} I L / \lambda$. We employed intensities of the order of $100 \mathrm{GW} /$ $\mathrm{cm}^{2}$. Because of possible uncertainties related to imperfect knowledge of the beam geometry and the temporal pulse shape (the pulses from the TOPAS are usually about $150 \mathrm{fs}$ fwhm, but precise knowledge of the pulse shape and the influence of chirp would require tedious autocorrelation/frequency resolved optical gating (FROG) studies), our measurements were always uniformly calibrated to the nonlinearity of silica glass; this avoids the need for detailed information of beam geometry and pulse shape and does not use the value of the intensity in the computation of the nonlinear properties of the sample. $^{21}$

The real and imaginary parts of the second hyperpolarizability, $\gamma$, of the solutes were computed assuming additivity of the nonlinear contributions of the solvent and the solute and the applicability of the Lorentz local field approximation. ${ }^{21}$ The values of the twophoton (TP) absorption (TPA) cross-section $\sigma_{2}$ were computed from the absorptive part of the nonlinearity determined from the Z-scans. In all cases, errors of the relevant quantities were estimated from the assessed accuracies of the parameters for the fitting of Z-scans for the solutions and the corresponding scans for the solvent.

Theoretical Studies. The TP matrix elements describing an instantaneous, resonant, absorption of two photons with identical energy have been computed through a residue of the quadratic response function. ${ }^{22}$ The corresponding sum-over-states expression for the TP matrix elements can be written as $^{23}$

$$
S_{\alpha \beta}=\sum_{k}\left[\frac{\left\langle 0\left|\mu^{\alpha}\right| k\right\rangle\left\langle k\left|\mu^{\beta}\right| f\right\rangle}{\omega_{k}-\omega_{f} / 2}+\frac{\left\langle 0\left|\mu^{\beta}\right| k\right\rangle\left\langle k\left|\mu^{\alpha}\right| f\right\rangle}{\omega_{k}-\omega_{f} / 2}\right]
$$

where $\omega_{k}$ and $\omega_{f}$ denote the excitation energies of the virtual $|k\rangle$ and the final $|f\rangle$ excited states, respectively, and $\mu^{\alpha}$ and $\mu^{\beta}$ are the components of the electric transition dipole moment operator along the molecular axis $\alpha, \beta=\{x, y, z\}$. The summation over the states also includes the ground state $|k\rangle=|0\rangle$. Having defined the TP matrix element, the TPA strength $\delta_{t p}$ in a viscous medium and for a linearly polarized radiation source ${ }^{24}$ is given by the expression:

$$
\delta_{t p}=\frac{1}{30} \sum_{\alpha \beta}\left(2 S_{\alpha \alpha} S_{\beta \beta}^{*}+4 S_{\alpha \beta} S_{\alpha \beta}^{*}\right)
$$

The conversion of computationally obtained $\delta_{t p}$ data (in atomic units) into a form that may be compared with experiment can be effected by assuming that the mechanisms of broadening of the transition are known. The TPA cross-section is often computed by assuming a relation such as the one below:

$$
\sigma_{0 f}^{(2)}=\frac{8 \pi^{3} \alpha_{0}^{5} \alpha}{c_{0}} \frac{\omega^{2} g(\omega)}{\Gamma_{f}} \delta_{t p}
$$

where $a_{0}$ is the Bohr radius, $c_{0}$ is the speed of light, $\alpha$ is the fine structure constant, and $\omega$ is the photon energy. Furthermore, $g(\omega)$ provides the normalized spectral line profile, and $\Gamma_{f}$ is the lifetime broadening of the final state, which is often assumed to be constant for different transitions, for example, equal to $0.1 \mathrm{eV} .^{25}$ The units

(20) Milam, D. Appl. Opt. 1998, 37, 546. 
Chart 2. Polyynediyl Complexes for Which Second Hyperpolarizabilities Have Been Measured in This Study

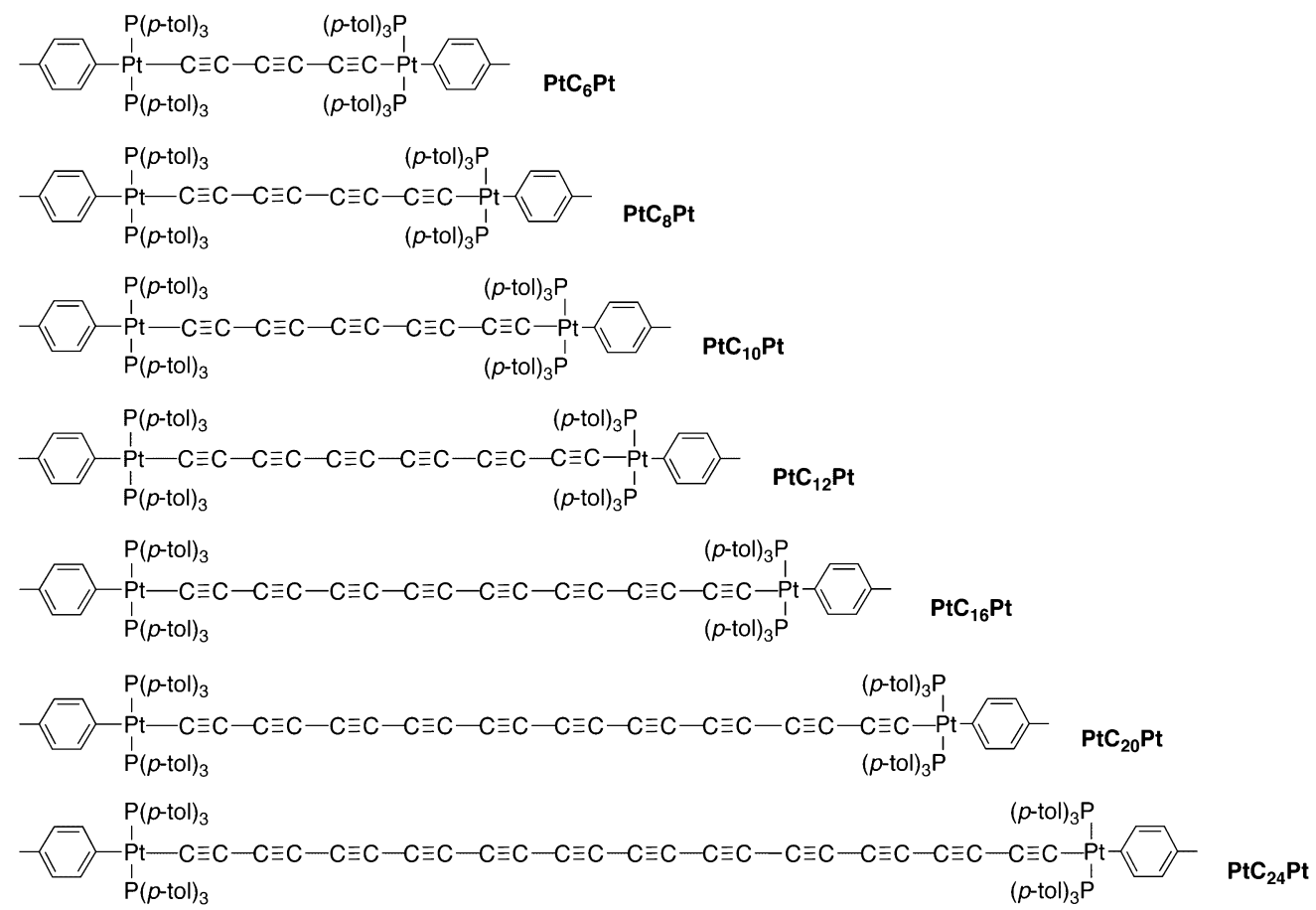

of $\sigma_{0 f^{(2)}}$ are then $\mathrm{cm}^{4} \mathrm{~s}_{\text {photon }}^{-1}\left(10^{-50} \mathrm{~cm}^{4} \mathrm{~s}_{\text {photon }}{ }^{-1}=1 \mathrm{GM}\right.$ $=1$ Goeppert-Mayer), providing that cgs units are used for $a_{0}$ and $c_{0}$, and atomic units are used for $\delta_{t p}, \omega$, and $\Gamma_{f}$.

All calculations in the present work were carried out at the Kohn-Sham density functional theory (DFT) level of theory. Molecular structures were optimized in the $D_{2 h}$ point group using the hybrid B3LYP ${ }^{26}$ density functional. For the light elements $(\mathrm{C}$, $\mathrm{H})$, the $6-31 \mathrm{G}(\mathrm{d})^{27}$ basis set was employed, whereas for the heavy elements (Pt, P), the Stuttgart (SDD) effective-core potentials $(\mathrm{ECPs})^{28,29}$ and the corresponding valence electron basis sets were employed. For the calculations of the molecular response properties, the Coulomb-attenuated hybrid functional CAM-B3LYP ${ }^{30}$ was used. Several basis sets were used in the response property calculations. For the light elements, the $6-31 \mathrm{G}^{27}$ and aug-cc$\mathrm{pVDZ}^{31}$ basis sets were used. The $\mathrm{SDD}^{28,29}$ and SDD $+(2 \mathrm{~d}, 3 \mathrm{f})$ basis sets were used for the heavy elements; in the latter case, the valence electron basis set is derived from the former one by addition of two d-type functions for phosphorus, three f-type functions for platinum, and a diffusive function for both elements.

The molecular structure optimizations were performed with the Gaussian program. ${ }^{32}$ The Dalton program $^{33}$ was used for all calculations of response properties; the version of the Dalton program that was employed includes an implementation of the CAM-B3LYP functional by Peach et al. ${ }^{34}$

(21) Samoc, M.; Samoc, A.; Luther-Davies, B.; Bao, Z.; Yu, L.; Hsieh, B.; Scherf, U. J. Opt. Soc. Am. B 1998, 15, 817.

(22) Olsen, J.; Jørgensen, P. J. Chem. Phys. 1985, 82, 3235.

(23) Shen, Y. R. The Principles of Nonlinear Optics; Wiley: New York, 1984.

(24) McClain, W. M. J. Chem. Phys. 1971, 55, 2789.

(25) Norman, P.; Luo, Y.; Ågren, H. J. Chem. Phys. 1999, 111, 7758.

(26) Becke, A. D. J. Chem. Phys. 1993, 98, 5648.

(27) Hehre, W. J.; Ditchfield, R.; Pople, J. A. J. Chem. Phys. 1972, 56, 2257.

(28) Fuentealba, P.; von Szentpaly, L.; Preuss, H.; Stoll, H. J. Phys. B $\mathbf{1 9 8 5}, 18,1287$.

(29) Kaupp, M.; Schleyer, P. v. R.; Stoll, H.; Preuss, H. J. Chem. Phys. 1991, 94, 1360.

(30) Yanai, T.; Tew, D. P.; Handy, N. C. Chem. Phys. Lett. 2004, 393, 51.

(31) Dunning, T. H., Jr. J. Chem. Phys. 1989, 90, 1007.

\section{Results and Discussion}

Experimental Studies. The cubic optical nonlinearities were evaluated by a combination of closed- and openaperture Z-scan experiments. Figure 1 shows a summary of the results obtained for all the compounds investigated in this work. In Figure 1, the hyperpolarizability dispersion data are plotted versus halved excitation wavelength and compared with one-photon (OP) absorption (OPA) spectra. This presentation of the data means that the energy scale of the $x$-axis refers to excitation energies of states rather than photon energies, and it allows for a direct comparison of excitation energies of $\mathrm{OP}$ and TP active states. Because of the symmetry

(32) Frisch, M. J.; Trucks, G. W.; Schlegel, H. B.; Scuseria, G. E.; Robb, M. A.; Cheeseman, J. R.; Montgomery, J. A., Jr.; Vreven, T.; Kudin, K. N.; Burant, J. C.; Millam, J. M.; Iyengar, S. S.; Tomasi, J.; Barone, V.; Mennucci, B.; Cossi, M.; Scalmani, G.; Rega, N.; Petersson, G. A.; Nakatsuji, H.; Hada, M.; Ehara, M.; Toyota, K.; Fukuda, R.; Hasegawa, J.; Ishida, M.; Nakajima, T.; Honda, Y.; Kitao, O.; Nakai, H.; Klene, M.; Li, X.; Knox, J. E.; Hratchian, H. P.; Cross, J. B.; Bakken, V.; Adamo, C.; Jaramillo, J.; Gomperts, R.; Stratmann, R. E.; Yazyev, O.; Austin, A. J.; Cammi, R.; Pomelli, C.; Ochterski, J. W.; Ayala, P. Y.; Morokuma, K.; Voth, G. A.; Salvador, P.; Dannenberg, J. J.; Zakrzewski, V. G.; Dapprich, S.; Daniels, A. D.; Strain, M. C.; Farkas, O.; Malick, D. K.; Rabuck, A. D.; Raghavachari, K.; Foresman, J. B.; Ortiz, J. V.; Cui, Q.; Baboul, A. G.; Clifford, S.; Cioslowski, J.; Stefanov, B. B.; Liu, G.; Liashenko, A.; Piskorz, P.; Komaromi, I.; Martin, R. L.; Fox, D. J.; Keith, T.; Al-Laham, M. A.; Peng, C. Y.; Nanayakkara, A.; Challacombe, M.; Gill, P. M. W.; Johnson, B.; Chen, W.; Wong, M. W.; Gonzalez, C.; Pople, J. A. Gaussian 03, Revision C.02; Gaussian, Inc.: Wallingford, CT, 2004.

(33) Angeli, C.; Bak, K. L.; Bakken, V.; Christiansen, O.; Cimiraglia, R.; Coriani, S.; Dahle, P.; Dalskov, E. K.; Enevoldsen, T.; Fernandez, B.; Hättig, C.; Hald, K.; Halkier, A.; Heiberg, H.; Helgaker, T.; Hettema, H.; Jørgen, H.; Jensen, Aa.; Jonsson, D.; Jørgensen, P.; Kirpekar, S.; Klopper, W.; Kobayashi, R.; Koch, H.; Ligabue, A.; Lutnas, O. B.; Mikkelsen, K. V.; Norman, P.; Olsen, J.; Packer, M. J.; Pedersen, T. B.; Rinkevicius, Z.; Rudberg, E.; Ruden, T. A.; Ruud, K.; Salek, P.; Sanchez de Meras, A.; Saue, T.; Sauer, S. P. A.; Schimmelpfennig, B.; Sylvester-Hvid, K. O.; Taylor, P. R.; Vahtras, O.; Wilson, D. J.; Ågren, H. DALTON, a molecular electronic structure program, release 2.0, 2005; see http://www.kjemi.uio.no/software/ dalton/dalton.html. 

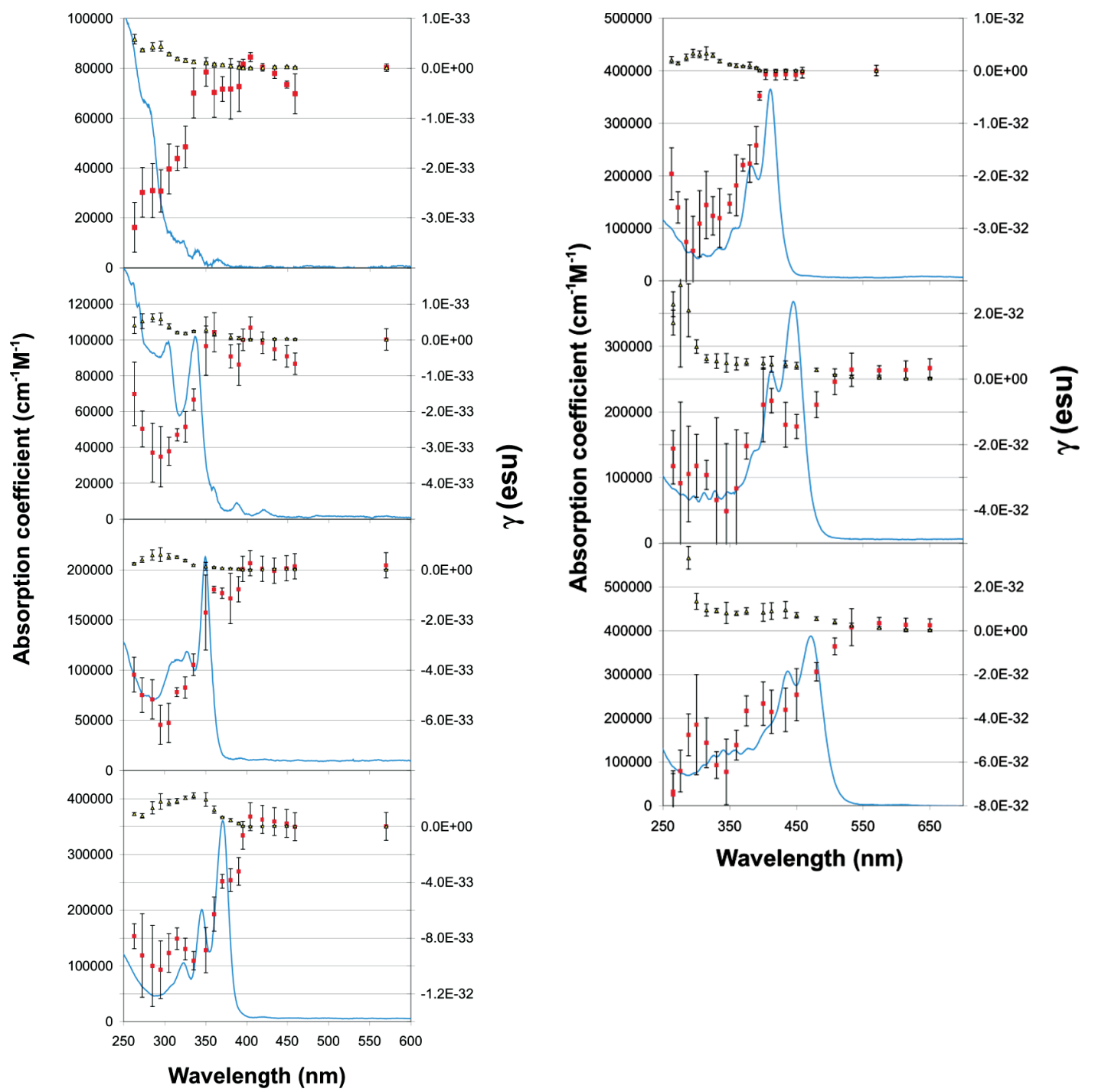

Figure 1. Dispersion of the real (squares) and imaginary (triangles) part of the degenerate second hyperpolarizability $\gamma(-\omega ; \omega,-\omega, \omega)$ for trans,trans-\{(p$\left.\left.\mathrm{MeC}_{6} \mathrm{H}_{4}\right)_{3} \mathrm{P}\right\}_{2}\left(p-\mathrm{MeC}_{6} \mathrm{H}_{4}\right) \mathrm{Pt}(\mathrm{C} \equiv \mathrm{C})_{n} \mathrm{Pt}\left(p-\mathrm{C}_{6} \mathrm{H}_{4} \mathrm{Me}\right)\left\{\mathrm{P}\left(p-\mathrm{C}_{6} \mathrm{H}_{4} \mathrm{Me}\right)_{3}\right\}_{2}$ (top to bottom, first column: $n=3\left(\mathbf{P t C} \mathbf{C}_{6} \mathbf{P t}\right), 4\left(\mathbf{P t C} \mathbf{C}_{8} \mathbf{P t}\right), 5\left(\mathbf{P t C} \mathbf{C}_{10} \mathbf{P t}\right), 6\left(\mathbf{P t C} \mathbf{C}_{12} \mathbf{P t}\right)$, second column: $\left.8\left(\mathbf{P t C}_{\mathbf{1 6}} \mathbf{P t}\right), 10\left(\mathbf{P t C}_{\mathbf{2 0}} \mathbf{P t}\right), 12\left(\mathbf{P t C}_{\mathbf{2}} \mathbf{P t}\right)\right)$. The lines in the graphs represent profiles of the OPA spectra of the compounds plotted against the wavelength. To facilitate comparison and evaluation of the influence of TP resonances, the real and imaginary parts of the complex hyperpolarizabilities are plotted against half the laser wavelength used.

of the compounds it is clear, however, that the same final states are not reached in the OPA and TPA processes: specifically, $u$ states are obtained for the OP process, while $g$ states are reached for the TP process. It should also be noted that, in general, there should be a Kramers-Kroniglike relationship between the real and imaginary parts of the second hyperpolarizability, similar to the well-known relationship between the real and imaginary parts of the linear polarizability. However, the situation is complicated by the fact that to obtain the real part of the degenerate $\gamma$ from the Kramers-Kronig relation requires knowledge of the nondegenerate TPA spectrum rather than the degenerate one obtained in the Z-scan experiment. ${ }^{35}$ Inspection of the

(34) Peach, M. J. G.; Helgaker, T.; Salek, P.; Keal, T. W.; Lutnæs, O. B.; Tozer, D. J.; C. Handy, N. C. Phys. Chem. Chem. Phys. 2006, 8, 558.

(35) (a) Sheikh-bahae, M.; Hagan, D. J.; van Stryland, E. W. Phys. Rev. Lett. 1990, 65, 96. (b) Samoc, M.; Samoc, A.; Humphrey, M. G.; Cifuentes, M. P.; Luther-Davies, B.; Fleitz, P. A. Mol. Cryst. Liq. Cryst. 2008, 485, 146. dependences seen in Figure 1 indicates that, despite the expected difference in the final states reached by the OP and TP absorption, there are some coincidences of the OPA features with features in both the real and imaginary parts of the hyperpolarizability. We also note the presence of inflections in the frequency dependences of the real part of $\gamma$ that in most instances correspond to resonances that are also seen in the imaginary part of $\gamma$.

Theoretical Studies. To rationalize the nonlinear absorption observations, DFT studies were undertaken on model complexes (Chart 3). The molecules in the present study are "one-dimensional", in the sense that their optical properties are determined by the electronic response along the conjugation axis (the $x$-axis with our choice of coordinate system: Figure 2). The electronic ground state is of a closed-shell character, that is, an $\mathrm{A}_{\mathrm{g}}$ state of singlet spin symmetry, and the HOMO-LUMO transition corresponds to the formation of an excited $\mathrm{B}_{3 \mathrm{u}}$ state. 
Chart 3. Examples of the Polyynediyl Model Complexes Employed in This Study
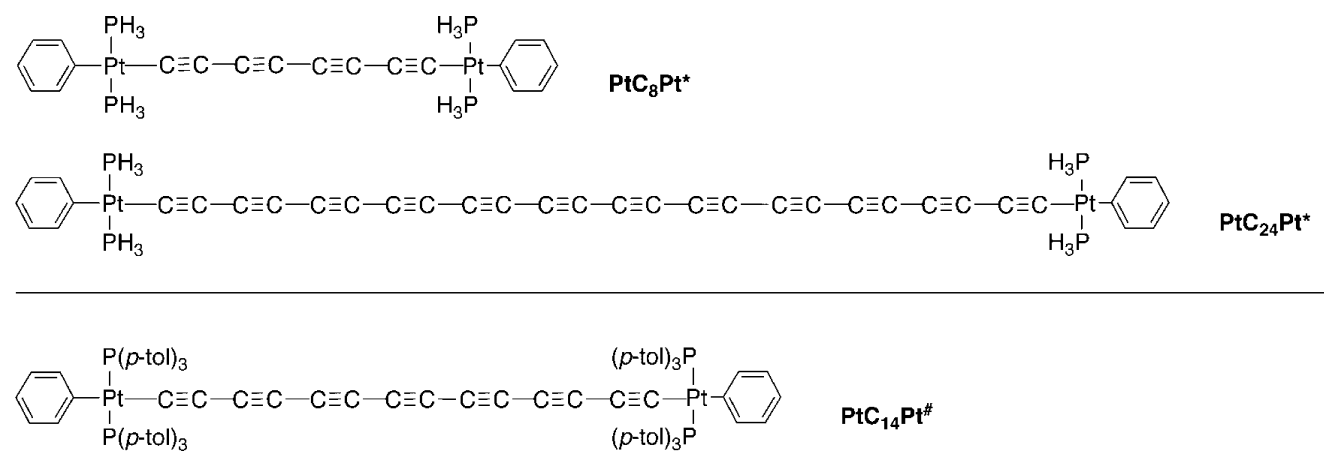

To reduce computational cost, the tri( $p$-tolyl)phosphine ligands of the complexes used in the experimental study were replaced with phosphine; Chart 3 depicts several examples. The optical properties are not significantly changed by this approximation because of the high degree of "one-dimensional" conjugation in these chromophores. This fact is illustrated in Figure 3 in which the fifth to seventh panels show the TPA strengths in the region 400-650 nm for the heptaynediyl complex with varying ligands. The fifth and seventh panels depict the TPA strengths obtained with phosphine $\left(\mathbf{P t C}_{\mathbf{1 4}} \mathbf{P t}^{*}\right)$ and tri( $p$-tolyl)phosphine ligands $\left(\mathbf{P t C}_{14} \mathbf{P t}^{\#}\right)$, respectively. As is seen by a comparison of the two panels, the difference in the calculated nonlinear response is small with respect to this change in the ligand environment, and, for the linear absorption spectrum, the difference is even smaller. Our computational studies have therefore employed $\mathrm{PH}_{3}$.

Apart from molecular structure approximations, the quality of our calculations depends on the parametrization of the electron density and the description of electron repulsion. We have chosen a hybrid exchange-correlation functional based on the Coulomb attenuating method, namely CAM$\mathrm{B} 3 \mathrm{LYP},{ }^{30}$ which is able to correctly treat electronic transitions that involve a hole-electron charge separation. Its level of accuracy in TPA calculations of valence transitions has been shown to be comparable to that obtained at the coupled cluster singles and doubles level of theory and superior to the accuracy reached with other standard adiabatic exchangecorrelation functionals. ${ }^{36}$ With respect to the parametrization of the one-particle electron density, we have employed several basis sets and evaluated them for the smallest system, for which the basis set sensitivity is expected to be greatest. Results from this investigation on $\mathbf{P t C} \mathbf{C}_{\mathbf{4}} \mathbf{P t}$ * are presented in the upper four panels of Figure 3. An inspection of the HOMO and LUMO in Figure 2 indicates that the strongest demands on the quality of the basis sets are expected for the carbon and platinum atoms; for carbon, we employed the all-electron basis sets 6-31G and aug-cc-pVDZ and for platinum (and phosphorus) we employed the SDD core potential and valence basis set with additional diffuse and polarization functions. From the upper four panels of Figure 3 we conclude that there is a red-shift in nonlinear absorption upon addition of polarization and diffuse functions on carbon

(36) Paterson, M. J.; Christiansen, O.; Pawlowski, F.; Jørgensen, P.; Hättig, C.; Helgaker, T.; Salek, P. J. Chem. Phys. 2006, 124, 54322. and platinum atoms, but that the relative intensities of the absorption bands are quite well described with the smallest basis set. Further support is provided by comparison of the fifth and sixth panels of the same figure, which illustrate the effects of polarization and diffuse functions on the heavy atoms of $\mathbf{P t C}_{14} \mathbf{P t}^{*}$. In summary, we believe that the CAMB3LYP/6-31G level of theory provides a relatively accurate portrayal (but somewhat blue-shifted because of the limited size of the basis set) of the electronic absorption properties of the compounds in the present study. Ro-vibrational and environmental effects are not taken into account in the theoretical simulations.

Some of us have previously reported the linear absorption spectra of the series $\mathbf{P t C}_{x} \mathbf{P t}^{*}{ }^{7 \mathrm{~d}}$ but we include here a brief presentation of the main absorption bands from our current study to use a consistent level of theory for linear and nonlinear absorption data. The present DFT studies on model complexes reveal that the electronic linear absorption spectra are largely determined by $\mathrm{X}^{1} \mathrm{~A}_{\mathrm{g}} \rightarrow \mathrm{n}^{1} \mathrm{~B}_{3 \mathrm{u}}$ transitions (other transitions are weak). Theoretical oscillator strengths and transition wavelengths for the main absorption bands in these diplatinum compounds are presented in Table 1 and compared to the experimental data.

For the smallest system $\mathbf{P t C}_{\mathbf{4}} \mathbf{P t}^{*}$, the lowest-energy transition is predicted by theory to occur at $334 \mathrm{~nm}$ with an oscillator strength of 0.597 . As the carbon chain length increases, this absorption band is red-shifted and reduced in intensity; for the pentaynediyl complex $\mathbf{P t C}_{10} \mathbf{P t}^{*}$; the longest wavelength transition is predicted to be at $434 \mathrm{~nm}$, with an oscillator strength 25 times smaller than that of the second absorption band. On the basis of the intensities, we believe that the correct assignment with respect to the experimental spectra is that the second and third bands at about 300 and $250 \mathrm{~nm}$ (the former band consisting of two electronic states) correspond to the experimental absorption maxima at 350 and $327 \mathrm{~nm}$. The discrepancies are large between theory and experiment; the theoretical transition wavelengths are much too short, and the band separation is overestimated in the theoretical calculations by some $25 \mathrm{~nm}$ for this compound. The overall and general shift in the theoretical transition energies (as compared to the experimental) is attributed to factors we have already mentioned, namely, (i) neglect of environmental and (ii) vibrational effects, (iii) the limited size of the basis set, and (iv) the use of model compounds. For the band separation, however, one would have expected 
Samoc et al.
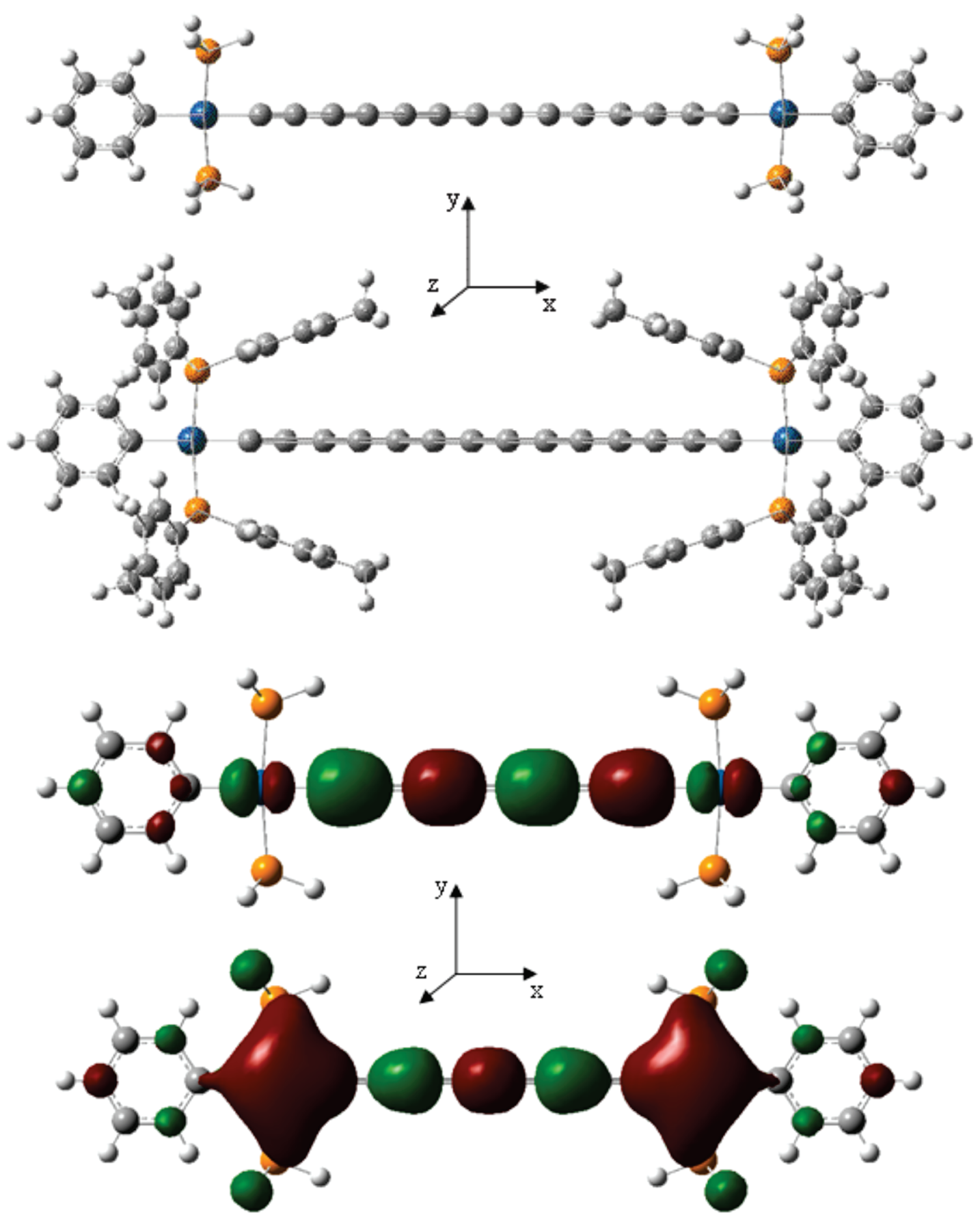

Figure 2. Top panel: trans,trans- $\left(\mathrm{H}_{3} \mathrm{P}\right)_{2}\left(\mathrm{C}_{6} \mathrm{H}_{5}\right) \mathrm{Pt}(\mathrm{C} \equiv \mathrm{C})_{7} \mathrm{Pt}\left(\mathrm{C}_{6} \mathrm{H}_{5}\right)\left(\mathrm{PH}_{3}\right)_{2}\left(\mathbf{P t C}_{14} \mathbf{P t} *\right)$. Second panel: trans, trans- $\left\{\left(p-\mathrm{MeC}_{6} \mathrm{H}_{4}\right)_{3} \mathrm{P}\right\}_{2}\left(\mathrm{C}_{6} \mathrm{H}_{5}\right) \mathrm{Pt}(\mathrm{C} \equiv \mathrm{C})_{7} \mathrm{Pt}\left(\mathrm{C}_{6} \mathrm{H}_{5}\right)\{\mathrm{P}(p-$ $\left.\left.\mathrm{C}_{6} \mathrm{H}_{4} \mathrm{Me}\right)_{3}\right\}_{2}\left(\mathbf{P t C}_{\mathbf{1 4}} \mathbf{P t}^{\#}\right)$. Third panel and fourth panel: Iso-density plots of the electron densities in the highest-occupied (third panel) and lowest-unoccupied (fourth panel) Kohn-Sham orbitals of $\mathbf{P t C}_{8} \mathbf{P t} *$.

these approximations to largely cancel out, so the discrepancy of $25 \mathrm{~nm}$ is noticeably large. The band separations are reduced with increasing molecular length, and this is a feature that is reproduced in the calculations. In further support of the assignments made in Table 1, we note that the ratio of the integrated intensities of the two experimental bands varies strongly for the series of compounds; it is equal to unity for $\mathbf{P t C}_{\mathbf{8}} \mathbf{P t}$, reaches a maximum for $\mathbf{P t C}_{16} \mathbf{P t}$, and then decreases on further chain lengthening. The same trend is observed for the theoretical oscillator strengths reported in the table.

For the longer chromophores, the main absorption occurs to states 2-4 of $\mathrm{B}_{3 \mathrm{u}}$ symmetry, and the calculations thus suggest that the first state of $\mathrm{B}_{3 \mathrm{u}}$ symmetry plays a diminishing role in the linear absorption spectrum upon oligoyne chain lengthening. The first state can, however, affect the nonlinear response properties most dramatically by resonance enhancement. We will return to this aspect in the discussion below.

The calculation of TPA spectra is computationally much more demanding than the calculation of the corresponding linear absorption spectra. The symmetry selection rules are, of course, different for OPA and TPA processes: whereas the gerade to ungerade selection rule governs OPA, it is the gerade to gerade selection rule that governs TPA. Again, 


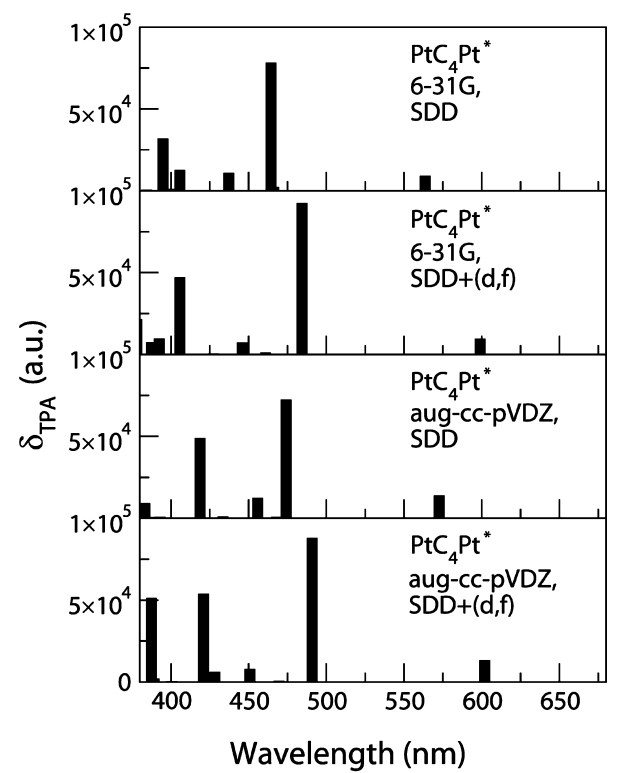

Table 1. Low-Energy Linear Absorption Bands for the Oligoynediyl Complexes

\begin{tabular}{|c|c|c|c|c|c|}
\hline & \multicolumn{2}{|c|}{ theory } & & \multicolumn{2}{|r|}{ expt } \\
\hline & $\lambda(\mathrm{nm})$ & $f_{\mathrm{OPA}}$ & & $\lambda_{\max }(\mathrm{nm})$ & $\varepsilon\left(10^{4} \mathrm{M}^{-1} \mathrm{~cm}^{-1}\right)$ \\
\hline \multirow[t]{3}{*}{$\mathrm{PtC}_{4} \mathrm{Pt}^{*}$} & 333.8 & 0.597 & $\mathrm{PtC}_{4} \mathrm{Pt}$ & & \\
\hline & 248.2 & 0.489 & & & \\
\hline & 236.1 & 0.788 & & & \\
\hline \multirow[t]{3}{*}{$\mathrm{PtC}_{6} \mathrm{Pt}^{*}$} & 356.5 & 0.427 & $\mathrm{PtC}_{6} \mathrm{Pt}$ & & \\
\hline & 273.3 & 1.483 & & 351 & 2.56 \\
\hline & 236.6 & 1.280 & & 329 & 3.36 \\
\hline \multirow[t]{3}{*}{$\mathrm{PtC}_{8} \mathrm{Pt}^{*}$} & 393.7 & 0.201 & $\mathrm{PtC}_{8} \mathrm{Pt}$ & & \\
\hline & 290.2 & 2.740 & & 337 & 10.2 \\
\hline & 241.2 & 2.073 & & 305 & 9.92 \\
\hline \multirow[t]{4}{*}{$\mathrm{PtC}_{10} \mathrm{Pt}^{*}$} & 433.9 & 0.100 & $\mathrm{PtC}_{10} \mathrm{Pt}$ & & \\
\hline & 303.4 & 2.490 & & 350 & 21.3 \\
\hline & 299.7 & 1.782 & & & \\
\hline & 249.4 & 2.880 & & 327 & 11.8 \\
\hline \multirow[t]{4}{*}{$\mathrm{PtC}_{12} \mathrm{Pt}^{*}$} & 471.5 & 0.058 & $\mathrm{PtC}_{12} \mathrm{Pt}$ & & \\
\hline & 313.7 & 5.724 & & 371 & 36.1 \\
\hline & 300.4 & 0.249 & & & \\
\hline & 261.0 & 2.817 & & 345 & 20.1 \\
\hline \multirow[t]{4}{*}{$\mathrm{PtC}_{14} \mathrm{Pt}^{*}$} & 513.4 & 0.035 & $\mathrm{PtC}_{14} \mathrm{Pt}$ & & \\
\hline & 327.6 & 7.576 & & & \\
\hline & 299.4 & 0.151 & & & \\
\hline & 278.4 & 2.061 & & & \\
\hline \multirow[t]{4}{*}{$\mathrm{PtC}_{16} \mathrm{Pt}^{*}$} & 533.4 & 0.025 & $\mathrm{PtC}_{16} \mathrm{Pt}$ & & \\
\hline & 338.4 & 8.725 & & 411 & 36.5 \\
\hline & 299.3 & 0.694 & & & \\
\hline & 296.0 & 1.245 & & 383 & 21.9 \\
\hline \multirow[t]{3}{*}{$\mathrm{PtC}_{20} \mathrm{Pt}^{*}$} & 580.5 & 0.014 & $\mathrm{PtC}_{20} \mathrm{Pt}$ & & \\
\hline & 365.5 & 9.649 & & 444 & 36.8 \\
\hline & 339.7 & 2.933 & & 413 & 26.2 \\
\hline \multirow{3}{*}{$\mathrm{PtC}_{24} \mathrm{Pt}^{*}$} & 614.6 & 0.009 & $\mathrm{PtC}_{24} \mathrm{Pt}$ & & \\
\hline & 393.5 & 5.687 & & 472 & 38.7 \\
\hline & 376.3 & 8.758 & & 437 & 30.7 \\
\hline
\end{tabular}

energy of the lowest OP states (see Table 1); even though the OPA cross-sections are low for these transitions, this will result in the TP matrix element diverging because of resonance. In an experiment, one expects that the OPA present at these frequencies may be followed by ESA and/ or absorption saturation that will compete with TPA, and the contributions of different nonlinear absorption processes may be difficult to deconvolute.

Discussion. The DFT studies shed light on the linear and since we are dealing with compounds with a highly "onedimensional" conjugation, the virtual transition from the intermediate state of $\mathrm{B}_{3 \mathrm{u}}$ symmetry in the TPA process is only symmetry allowed for a final state of $\mathrm{A}_{\mathrm{g}}$ symmetry, and we have restricted our presentation of TPA spectra to include only states of this symmetry.

The TPA cross-sections for this series of compounds are presented in Figure 4 (and in Table 2: see later). For each molecule we have included the 10 lowest-energy singlet states of $\mathrm{A}_{\mathrm{g}}$ symmetry, which is a selection that, for compounds up to $\mathbf{P t C}_{12} \mathbf{P t}^{*}$, covers the visible wavelength region $(400-700 \mathrm{~nm})$. For complexes with longer conjugation length, we do not resolve states in the near UV region. The general trend in the TPA spectra is a red-shift and a narrowing of the TPA profile with increasing conjugation length. For the longest complex, $\mathbf{P t C}_{24} \mathbf{P t}$ *, the TP intensity is focused at a single state at $620 \mathrm{~nm}$. The integrated TPA cross-section in the visible region is enhanced by a factor of about 100 in proceeding from the shortest to the longest chromophore. In Figure 4 we have excluded one TP transition each for $\mathbf{P t C}_{\mathbf{2 0}} \mathbf{P t} *$ and $\mathbf{P t C}_{\mathbf{2 4}} \mathbf{P t} *$. These two TP transitions occur at energies that equal twice the transition nonlinear absorption spectra. As was mentioned above, the calculations reveal a plethora of electronic transitions, those with the highest calculated oscillator strengths being listed in Table 1. The pattern of the transition energy changes observed upon lengthening the carbon chain correspond fairly well with the absorption features in the experimental spectra. The uniform red-shift observed in proceeding from calculated to experimentally obtained absorption maxima probably derives from several factors, one being that the computations correspond to gas-phase molecules while the experimental spectra derive from solution measurements in the moderately polar solvent dichloromethane.

Comparison of the experimental and theoretical TPA data is not trivial, one reason being that the computations afford discrete transitions while the experiments show relatively broad bands which may involve a range of broadening mechanisms as well as overlap of multiple TP transitions with various electronic and vibrational contributions. A possible way of dealing with this situation is comparison of integrated TPA strengths. ${ }^{37}$ The character of the present 
Samoc et al.
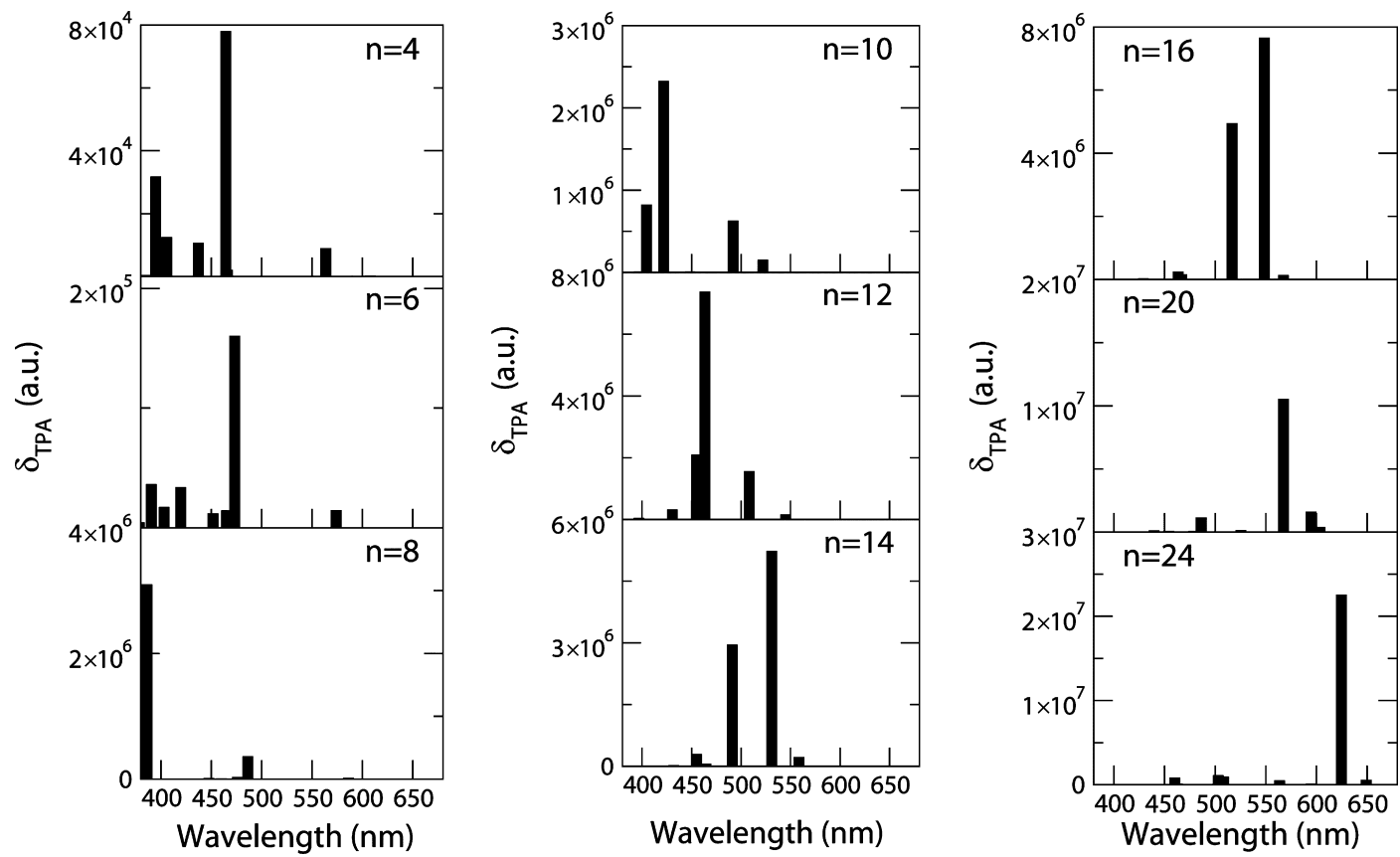

Figure 4. TPA cross-sections for $\mathbf{P t C}{ }_{n} \mathbf{P t} *(n=4,6,8,10,12,14,16,20,24)$. The intruder terms in the calculated TPA spectra of $\mathbf{P t C}{ }_{20} \mathbf{P t} *$ and $\mathbf{P t C} \mathbf{C}_{24} \mathbf{P t} *$ have been excluded.

experimental data suggests treatment in terms of the overlap of several transitions, leading to an approximately Gaussian shape of the dominant TP band.

Figure 5 illustrates the dispersion of the nonlinear absorption plotted as the TPA cross-sections, $\sigma_{2}$, expressed in Goeppert-Mayer units. One should note that the profiles of the wavelength dependences of $\sigma_{2}$ are essentially those of the imaginary part of $\gamma(-\omega ; \omega,-\omega, \omega)$, presented in Figure $1, \sigma_{2}$ being proportional to $\operatorname{Im}[\gamma(-\omega ; \omega,-\omega, \omega)] / \lambda$. The dominant $\sigma_{2}$ band for all but the longest of the carbon chains may be approximated by a simple Gaussian:

$$
\sigma_{2}(\bar{v})=\sigma_{2, \max } \exp \left[-\frac{\left(\bar{v}-\bar{v}_{\max }\right)^{2}}{2 \Gamma^{2}}\right]
$$

For the complexes with the longer carbon chains, the spectra are increasingly dominated by very high values of the TPA cross-sections at short wavelengths. These wavelengths coincide with the onset of $\mathrm{OP}$ transition, and therefore the increase is most likely due to the influence of OP resonances, as mentioned by us above and as described by several authors. ${ }^{38}$

Table 2 compares TPA strength for selected transitions obtained from the computational studies with those from the experimental studies, the latter corresponding to curves of the integrated Gaussian fits. Because of the presence of numerous overlapping transitions, as well as the accuracy of the experimental data, it is not possible to identify individual component transitions (each of which can also contain vibrational structure) in the rather broad experimental TPA spectra. The use of eq 3 for conversion of theoretical TP strengths into TPA cross-sections using a preassumed damping factor $\Gamma_{f}$ is therefore not useful for comparison with experiment. In Table 2 we compare selected TP strengths obtained from the computations with the experimental analogue of the theoretical TP strength, which is obtained by integration of the TP spectra.

We note that the relation between the experimental TP cross-section and the theoretically obtained TP strength can be written as

$$
\sigma_{0 f}=\frac{(2 \pi \mathrm{e})^{4}}{\left(4 \pi \varepsilon_{0}\right)^{2} c^{2} h^{2}} g(v) \omega^{2} \delta_{0 f}=4 \pi^{2} \alpha^{2} g(v) \omega^{2} \delta_{0 f}
$$

where $\alpha$ is the fine structure constant and $g(v)$ is the normalized band shape function. ${ }^{37 a}$ Assuming that the shape of the experimental TP cross-section versus frequency spectrum comes from the band shape function only, one can integrate the above equation as below:

$$
\int \sigma_{2}(v) \mathrm{d} v=4 \pi^{2} \alpha^{2}\left[\int g(v) \mathrm{d} v\right] \omega_{\max }^{2} \delta_{0 f}=4 \pi^{2} \alpha^{2} \omega_{\max }^{2} \delta_{0 f}
$$

Thus, the integrated TP cross-sections can be used to calculate the experimental TPA strengths given in Table 2.

Both computational and experimental studies reveal TPA maxima that red-shift and increase in intensity with increasing polyynediyl chain length. The experimental maxima are significantly red-shifted compared to the corresponding computational maxima, while the latter are also more than an order of magnitude larger. The differences in absolute values for nonlinear absorption may result from a number of factors. Geometries were optimized with $D_{2 h}$ symmetry to minimize computational expense, while structural data (admittedly solid-state, and therefore subject to crystal packing forces) reveal bowed or S-shaped polyynediyl chains for differing termini; ${ }^{8}$ one would anticipate that the enforced

(37) See, for example: (a) Poulsen, T. D.; Frederiksen, P. K.; Jorgensen, M.; Mikkelsen, K. V.; Ogilby, P. R. J. Phys. Chem. A 2001, 105, 11488. (b) Fortrie, R.; Chermette, H. J. Chem. Phys. 1996, 124, 204104. 

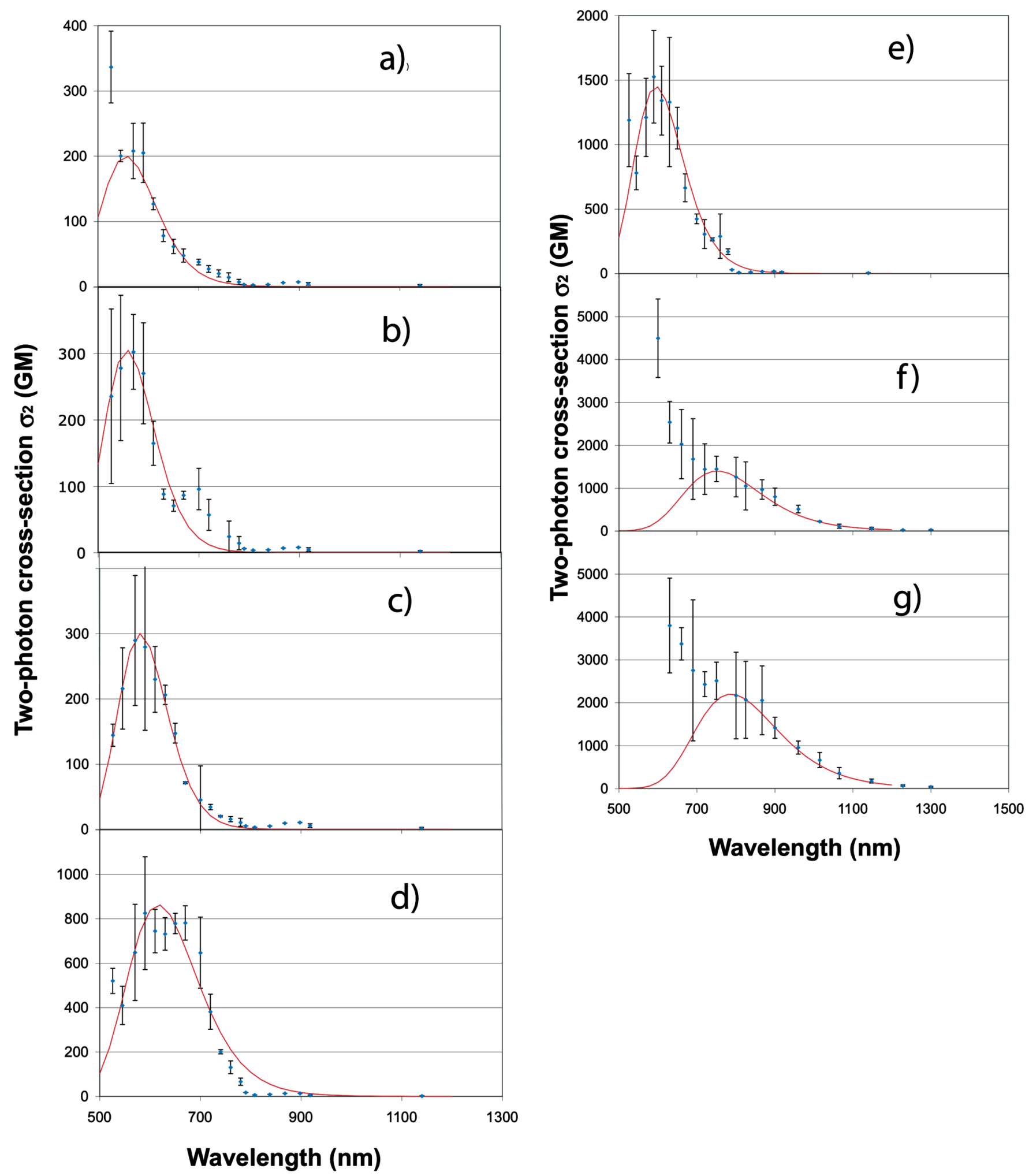

Figure 5. TP cross-sections of $\mathbf{P t C}_{6} \mathbf{P t}$ (a), $\mathbf{P t C} \mathbf{C}_{8} \mathbf{P t}$ (b), $\mathbf{P t C} \mathbf{C}_{10} \mathbf{P t}$ (c), $\mathbf{P t C} \mathbf{C}_{12} \mathbf{P t}(\mathrm{d}), \mathbf{P t C} \mathbf{C}_{16} \mathbf{P t}$ (e), $\mathbf{P t C} \mathbf{C}_{20} \mathbf{P t}$ (f), and $\mathbf{P t C} \mathbf{C}_{24} \mathbf{P t}$ (g) plotted against the laser wavelength. The full lines are Gaussian fits described in the text.

symmetry with its enhanced $\pi$-overlap would result in increased nonlinearity. It is well-known that DFT TPA crosssections tend to be overestimated by B3LYP (the excitation energies tend to be underestimated), and in the present system this overestimation may be insufficiently compensated by CAM-B3LYP.
We stated earlier that the experimental TPA spectral profiles can be approximated by Gaussian fits that afford the TPA maxima. Figure 6 shows the relationship between linear and nonlinear absorption maxima and the reciprocal of the number of carbons; neglecting saturation, extrapolation to the $y$-intercept provides an indication of the infinite carbon 
Samoc et al.

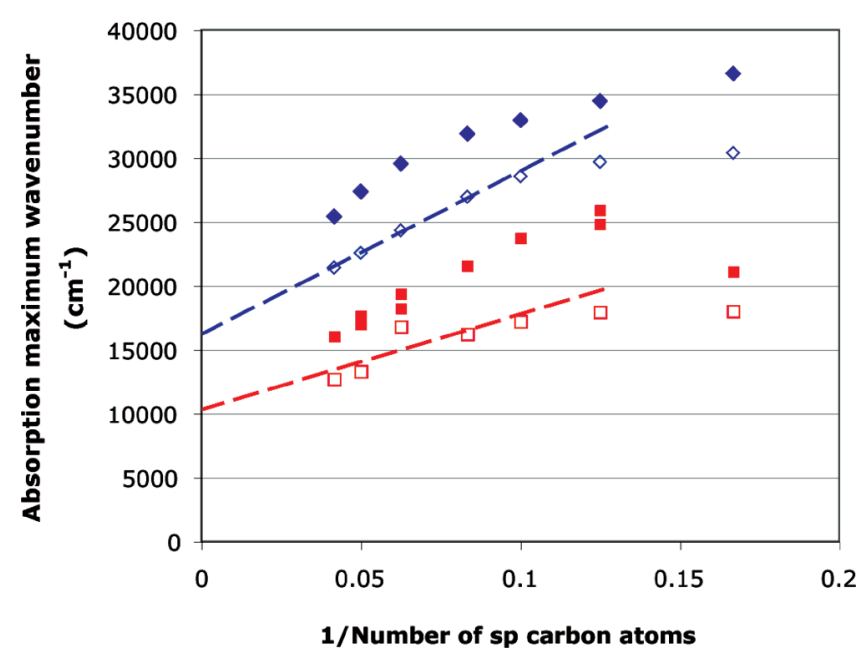

Figure 6. Positions of the dominant OPA peak (diamonds) and TPA peak (squares) plotted against the inverse of the number of carbon atoms. Open symbols denote experimental values, while filled symbols are the computational values.

chain behavior, that is, carbyne. Several previous studies have explored the linear absorption maxima-chain length relationship, ${ }^{5,6 b, 7 a, b, d}$ for which values in the range 550-575 $\mathrm{nm}$ have been obtained; in the present study, extrapolation of the energy as a function of $1 / n$ gives a value of about $660 \mathrm{~nm}$ (ca. $16100 \mathrm{~cm}^{-1}$ ). This is the first wavelengthdependence study of nonlinear absorption for an sp-carbon chain-containing series, our data suggesting that the TPA maximum for carbyne will occur at about $1000 \mathrm{~nm}$.

The relationship between magnitude of TPA maxima and chain length is explored in Figure 7. The length dependence of refractive nonlinearity in the tri(isopropyl)silyl-functionalized oligoynes in Chart 1 has been examined, an enhanced power dependence being found, ${ }^{6 \mathrm{~b}}$ but this may to some extent reflect the single-wavelength conditions employed. The present studies are the first to assess the relationship between TPA and sp-carbon chain length, revealing a superlinear increase in $\sigma_{2}$, max on chain lengthening that can be fitted as a power law dependence with an exponent of about 1.8, while for the real part of the hyperpolarizability the exponent is about 2.5. It should be noted that no correction for the contribution of the $\mathrm{Pt}\left(p-\mathrm{C}_{6} \mathrm{H}_{4} \mathrm{Me}\right)\left\{\mathrm{P}\left(p-\mathrm{C}_{6} \mathrm{H}_{4} \mathrm{Me}\right)_{3}\right\}_{2}$ moieties to $\sigma_{2}$ and $\gamma_{\text {real }}$ has been adopted here. Factoring in such a correction would increase the values of the exponents, but the current data scatter does not allow for a reliable determination of such parameters (for example, a leastsquares fitting leads to $\sigma_{2}=5.6+\left(20.35 \times n^{1.8915}\right)$ and $\left|\gamma_{\text {real }}\right|$
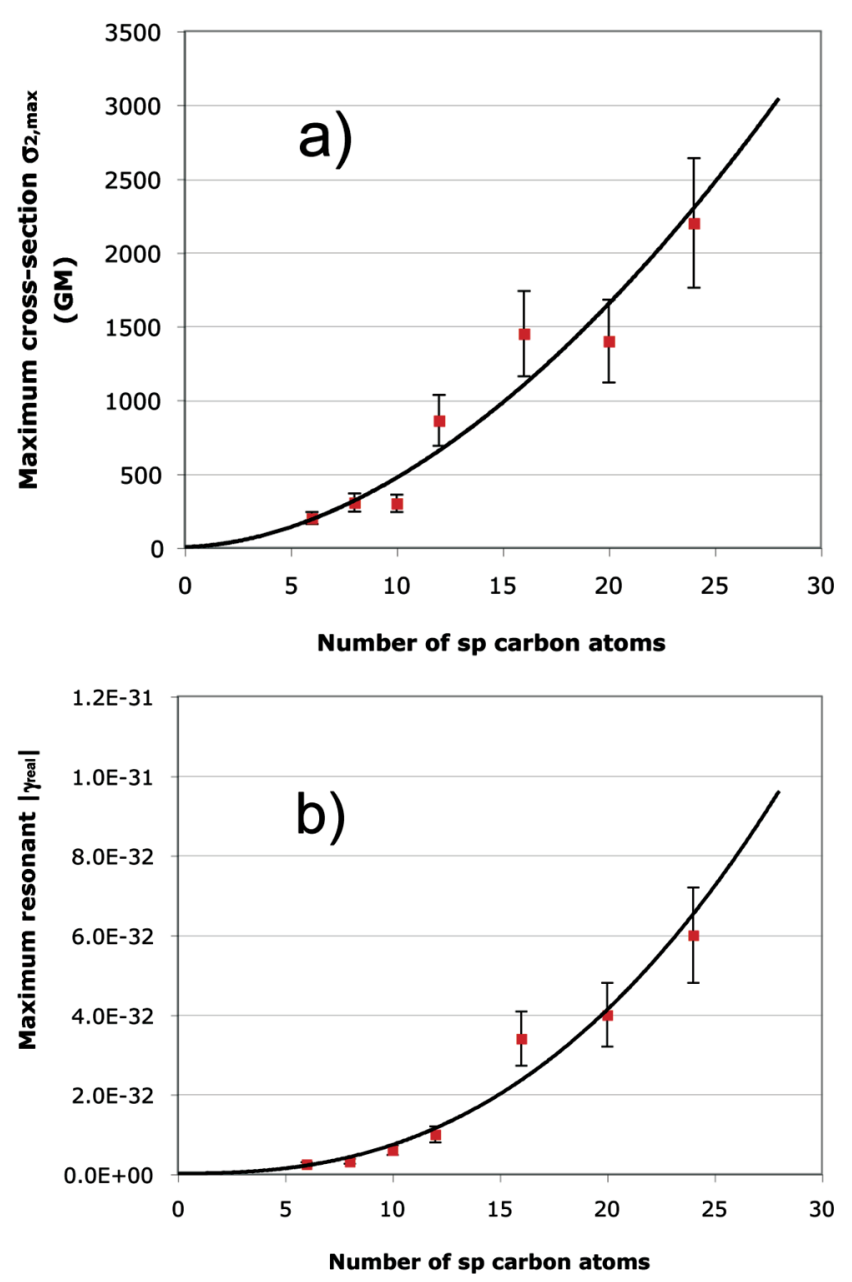

Figure 7. (a) Fitting parameter $\sigma_{2}$,max and (b) the resonant $\left|\gamma_{\text {real }}\right|_{\max }$ (corresponding to values of the parameter at about $32000-35000 \mathrm{~cm}^{-1}$ ) plotted against the number of carbons. The lines represents fitted power dependences $\sigma_{2}=7.05 \times n^{1.52}$ and $-\gamma_{\text {real }}=\left(2.12 \times 10^{-35}\right) \times n^{2.52}$. In both cases a zero intercept was assumed.

$=\left(6.9 \times 10^{-36}\right)+\left\{\left(9.8 \times 10^{-35}\right) \times n^{2.8995}\right\}$ for the data in panels a and $b$ of Figure 7, respectively, but the resulting dependences are difficult to distinguish from those calculated without the offsets).

\section{Conclusion}

This series of ligated platinum-stabilized oligoynes has allowed the first assessment of the sp-carbon chain lengthdependent evolution of cubic NLO properties, thereby providing an informed estimate of the behavior of the infinite sp-carbon chain species carbyne. The data suggest that

Table 2. TPA Strength from the Computational and Experimental Studies

\begin{tabular}{|c|c|c|c|c|c|c|c|}
\hline & \multicolumn{2}{|c|}{ computational data } & & \multicolumn{4}{|c|}{ experimental data } \\
\hline & $\lambda(\mathrm{nm})$ & $\delta_{\mathrm{TPA}}($ a.u. $)$ & & $\lambda(\mathrm{nm})$ & $\sigma_{2}, \max (\mathrm{GM})$ & $\Gamma\left(\mathrm{cm}^{-1}\right)$ & $\delta_{\mathrm{TPA}(\exp )}$ \\
\hline $\mathrm{PtC}_{6} \mathrm{Pt}^{*}$ & & & $\mathrm{PtC}_{6} \mathrm{Pt}$ & 329 & 200 & 1767 & 24200 \\
\hline $\mathrm{PtC}_{10} \mathrm{Pt}^{*}$ & $\begin{array}{l}500.2 \\
421.7\end{array}$ & $2.32 \times 10^{6}$ & $\mathrm{PtC}_{10} \mathrm{Pt}$ & 350 & 300 & 1440 & 32400 \\
\hline $\mathrm{PtC}_{12} \mathrm{Pt}^{*}$ & 463.5 & $7.36 \times 10^{6}$ & $\mathrm{PtC}_{12} \mathrm{Pt}$ & 371 & 862 & 1827 & 133000 \\
\hline $\mathrm{PtC}_{16} \mathrm{Pt}^{*}$ & 548.6 & $7.64 \times 10^{6}$ & $\mathrm{PtC}_{16} \mathrm{Pt}$ & 411 & 1450 & 1752 & 200000 \\
\hline $\mathrm{PtC}_{20} \mathrm{Pt}^{*}$ & 567.4 & $1.05 \times 10^{7}$ & & & & & \\
\hline $\mathrm{PtC}_{24} \mathrm{Pt}^{*}$ & 624.6 & $2.25 \times 10^{7}$ & $\mathrm{PtC}_{24} \mathrm{Pt}$ & 467 & 2200 & 1697 & 514000 \\
\hline
\end{tabular}


carbyne TPA will peak at about $1000 \mathrm{~nm}$. Interestingly, TPA strength increases markedly on chain lengthening-given that saturation has not been reached in the present study, longer chain examples will have extraordinarily large TPA/MWt values. The theoretical studies are in broad agreement with the experimental results, the calculations predicting the redshift and increase in intensity of TPA maxima that are observed experimentally, and the lack of exact correspondence of magnitude highlighting the difficulty of accurate calculation of TPA properties of transition metal-containing species.

Acknowledgment. We thank the Australian Research Council (M.G.H., M.S.; Australian Professorial Fellowship,
M.G.H.), the Alexander von Humboldt-Stiftung (Fellowship to M.G.H., Universität Erlangen-Nürnberg), the Deutsche Forschungsgemeinschaft (SFB 583, J.A.G), the U.S. National Science Foundation (CHE-0719267, J.A.G.), the nanoprogram run jointly by the Swedish Materiel Administration and the Swedish Defence Research Agency (H.A.), the Swedish Science Research Council (H.A.), and the STINT Foundation (Y.V.) for support.

IC801145C

(38) (a) Kamada, K.; Ohta, K.; Iwase, Y.; Kondo, K. Chem. Phys. Lett. 2003, 372, 386. (b) Drobizhev, M.; Karotki, A.; Kruk, M.; Rebane, A. Chem. Phys. Lett. 2002, 355, 175 . 